\title{
Normocalcaemic tetany after parathyroidectomy for hyperparathyroidism
}

\author{
U.Aziz, R.Mallik, S.Ponnampalam, A.Rathore \\ Southend University Hospital, Westcliff on Sea, Essex, UK
}

\section{Introduction}

Hypocalcaemia is a frequent complication after thyroid and parathyroid surgery. We report a case of tetany occurred in a patient post parathyroid surgery with normocalcemia, normophosphotaemia and normomagnesaemia .

\section{Case History}

A 55 year old male Caucasian patient referred by general physician with vague three month history of fatigue, loss of appetite intermittent constipation and abdominal pain. Systemic examination unremarkable.

\section{Investigations and results}

His investigations were keeping with primary hyperparathyroidism with adjusted Ca raised at $3.3 \mathrm{mmol} / \mathrm{I}$. Parathyroid USS and isotope scan both reported right inferior parathyroid adenoma which was removed . 24 hours Post surgery his calcium levels were $2.7 \mathrm{mmol} / \mathrm{I}$ and subsequently $2.3 \mathrm{mmol} / \mathrm{l}$. He presented in A/E twice with severe spasms of the hands and legs with positive Trassuea's sign. His magnesium and phosphate levels were both normal at $0.82 \mathrm{mmol} / \mathrm{l}$ and $0.96 \mathrm{mmol} / \mathrm{l}$.

He was started on calcichew and his serum calcium levels had risen from 2.27 to $2.46 \mathrm{mmol} / \mathrm{l}$. There was no drastic change in his symptoms. Interestingly he had ongoing symptoms of Parkinson's disease and was also started on Sinmet 1 tablet 5 times a day. From parathyroid surgery he had excellent outcome but reviewing his symptoms retrospectively if during his presentations in acute assessment unit if IV calcium would have been given this would have differentiated more clearly improvement in his symptoms and signs.

\section{Conclusion}

Our patient presented with unusual symptoms of hypocalcemia despite of normal levels of calcium and magnesium suggesting that patients with long standing hypercalcaemia showed persistent neuromuscular irritability inspite of normocalcaemia affecting daily activities but this case presented the difficult dilemma of overlapping symptoms of Parkinson's in such cases should be carefully considered and where possible to differentiate alleviation of symptoms with IV calcium.

References.

Hypocalcemia after thyroid and parathyroid surgery and its' treatment Mehmet Uludağ 